\title{
A terceira margem da história. Apontamentos em volta de As duas faces da guerra de Diana Andringa e Flora Gomes
}

\author{
Livia Apa \\ (Università degli Studi di Napoli "L'Orientale")
}

\section{RESUMO}

O texto pretende abordar, partindo do documentário As duas faces da guerra, de autoria da jornalista portuguesa Diana Andringa e do realizador guineense Flora Gomes, o tema do conflito das memórias e reflectir sobre como os arquivos de imagens podem funcionar no processo de construção de uma memória colectiva e partilhada. Neste sentido, o documentário em questão parece apresentar um percurso que perpassa a questão da "guerra de memórias" propondo uma leitura comum das estórias ocorridas na frente da Guiné durante a guerra colonial, propondo uma leitura dos factos que visa salientar como, de acordo com quanto afirmava Amílcar Cabral, o destino das duas partes, neste caso Portugal e Guiné Bissau, estava ligado de forma indissolúvel.

PALAVRAS-CHAVE: memória, guerra, imagem, arquivo.

\section{ABSTRACT}

The essay intends to approach, with the documentary As duas faces da guerra authored by the Portuguese journalist Diana Andringa and the Guinea producer Flora Gomes as a starting point, the theme of the memories in conflict, and to reflect upon the manners in which the image archives may function in the process of construction of a collective and shared memory. In this sense, the Portuguese documentary in question seems to present a route that passes by the issue of the gmemories war $h$, proposing a common reading of the histories which occurred on the Guinean front during the colonial war; proposing a reading of the facts which stress how, in accordance to what Amílcar Cabral affirmed, the fate of the two sides, in this particular case, Portugal and GuineaBissau, were indissolubly connected.

KEYWORDS: memory, war, image, archive 
"Cheguei ao cinema por uma questão política: a imagem não tem nacionalidade"

Abderaman Sissako

"O cinema para mim é promessa de possibilidade e de potencialidades: é o guardião de uma forma de aprendizagem das potencialidades e possibilidades de um certo saber africano"

John Akomfrah

"Estamos perante uma guerra que não admite testemunhas" Jean Lamore

Acompanho há alguns anos o trabalho de um amigo fotógrafo, Patrizio Esposito. Patrizio, tem vindo a viajar incansavelmente por vários lugares do planeta. O seu olhar tenta captar fragmentos de estórias, momentos de vida dos muitos seres humanos que parecem ser destinados a nunca ter voz, a nunca ganhar existência no grande fluxo da História. Em tempos mais recentes, Patrizio, tem vindo a dedicar-se à causa do povo sahrawi. Como todos sabemos, a seguir de 1975, ano em que a Espanha abandona a antiga colónia do Sahara Ocidental, o Reino de Marrocos tem ocupado boa parte dos territórios sahrawi, obrigando estas populações a retirar-se e a viver no meio do deserto da Hammada, em acampamentos precários. Marrocos está sobretudo negando a própria existência desse povo e da luta que ele quotidianamente trava para o seu direito a existir. Como consequência, qualquer memória do conflito que a Frente Polisário e a população resistente ao poder marroquino tem vindo a desempenhar, é constantemente apagada e não consegue chegar a ter consistência suficiente nos meios de comunicação social e junto da comunidade internacional.

Patrizio achou então que devia haver maneira de falar de tudo isto, percebendo logo que era preciso documentar o silêncio, para devolver existência à luta dos 200.000 refugiados que entretanto passaram a viver nos campos do deserto argelino. Descobre então que no Museu da Guerra, que tinha sido organizado nos campos do deserto de Hammada, havia imensas fotografias. Tratava-se de uma tipologia de fotos muito especial: eram imagens do inimigo, dos seus afectos, na maior parte dos casos, fotografias retiradas a soldados marroquinos prisioneiros ou vítimas de acções de guerrilha operadas pela Frente Polisário. Elas, na sua simplicidade, são a prova patente da existência daquele conflito negado pelo rei Hassan II e pelo seu herdeiro. Eram e são fragmentos de um "amor interrompido" como diz Jean Lamore, um impressionante arquivo de caras de familiares, crianças, esposas, irmãos, velhos pais, árvores ao pé de pobres casas de campo, alguma paisagem. Uma galeria que nos induz a reflectir sobre o drama individual dos protagonistas de qualquer conflito, sobre a suspensão de qualquer relação entre o individuo e os seus afectos e a sua pessoal geografia. Caras, as caras dos que amamos, ou estilhaços de uma geografia vivencial (uma casa, uma árvore, um campo), único fio capaz de nos manter em vida em situações extremas. Patrizio começou então a contar esta guerra ao contrário, pelo avesso, 
partindo do rosto do inimigo. Reuniu pacientemente os matérias, gravou arquivos sonoros, organizou um livro só de imagens, que mandou imprimir em apenas 20 exemplares, que ao longo do tempo estão a ser confiados a um igual numero de guardiões (José Saramago foi um deles). Todos os anos, e já há alguns anos, Patrizio visita casas particulares, onde reúne pessoas que querem ouvir as histórias desta guerra de libertação esquecida. O projecto chama-se "Necessità dei volti" (A urgência dos rostos), e foi, até agora, apresentado em quase 200 casas em vários países do mundo.

Houve um encontro também em Lisboa, em casa do escritor e jornalista Pedro Rosa Mendes e foi para mim ocasião por me dar conta de uma obviedade: em cada guerra se fala de multidões, tropas, vítimas, mas seria, pelo contrário, necessário, para contar a sua história mais profunda, evocar cada um dos rostos escondidos, um por um, para reconstruir "o tecido rasgado da memoria" fio por fio, para renovar uma memória realmente partilhada entre homens e mulheres que habitam um determinado espaço físico, que se alimente exactamente pela fragmentação do processo de reconciliação mnemónica demasiadas vezes consolidadas pela construção discursiva do poder.

\section{1.}

Se, logo a seguir à independência das antigas colónias portuguesas, se pode contar um acervo de livros, na maior parte edições de autor, nas quais militares ou simples "retornados" contavam a "sua verdade" sobre o processo de descolonização e as guerras de libertação, é apenas nos últimos anos que temos vindo a assistir, no mercado editorial português, a uma crescente atenção para com as memórias dos últimos anos da presença portuguesa no outrora chamado Ultramar. O caminho, aberto, no meu entender, por livros como Lourenço Marques (2002) de Francisco José Viegas e o grande best-seller Equador (2003) de Miguel Sousa Tavares, chegado em 7 anos à $21^{\text {a. }}$ edição, parece de facto inesgotável. Trata-se, na maior parte dos casos, de memórias conciliadoras em que pouco ou nada se refere da questão colonial entendida como problema, preferindo, porém, um enfoque que mais tem a ver com uma perspectiva que podemos rotular, algo redutivamente, de saudosista. Foi a seguir a esta emergência de textos que o mercado editorial começou por ser invadido também por álbuns de fotos que retratavam um vago "antigamente", quando se tratava pelo contrário de um tempo relativamente recente que remontava, na maioria dos casos, aos anos da importante vaga de colonização sobretudo de Angola e Moçambique, dos anos 50 e dos imediatamente a seguir. Isto porque os protagonistas daquela fase, ou os filhos deles, podem hoje em dia constituir um núcleo duro de fruidores/consumidores, em termos de mercado, daquelas memórias tão difíceis de partilhar com a nova cara da contemporaneidade de Portugal, toda virada por duas décadas, como nos ensina Eduardo Lourenço, para a Europa.

Depois de uma campanha de recalcamento obstinado e massivo, esta "nova" literatura que muito parece refazer-se à estética da literatura colonial e ultramarina, faz voltar África à tona, também através da publicação de álbuns de postais, fotografias, DVDs, que apelam para uma espécie de dolce vitanas colónias e de idade áurea do império. Todo este 
manancial de imagens acaba por constituir um espaço comum de recordo, livre daquilo que foi o horror da guerra colonial, que se coloca numa direcção diametralmente oposta àquela "urgência de dizer" manifestada pelo romance da guerra colonial. Faltou, neste contesto e durante muito anos, uma narração por imagens que não fossem apenas as que pertencem a famílias, grupos de ex-combatentes, isto é imagens capazes de criar um espaço publico, capaz de ir ao encontro de uma narrativa comum tanto na antiga metrópole como nas antigas colónias. Excepções a esta regra geral me parecem ser uns poucos títulos. Refirome, entre outros, obviamente ao matricial Um adeus português de João Botelho (1986), mas também a Os Imortais de António Pedro Vasconcelos (2003), que coloca a questão da dificuldade de reintegração na sociedade portuguesa dos comandos da guerra do Ultramar e da Costa dos Murmúrios de Margarida Cardoso (2004), realizado a partir do homónimo romance de Lídia Jorge.

Vale a pena frisar provavelmente que ao nível da reconstrução de uma memória dos últimos anos da presença colonial portuguesa em África, nos mesmos anos em que saem os filmes de Vasconcelos e Cardoso e os livros de Sousa Tavares e Viegas, acima referidos, tem grande êxito em Portugal uma telenovela $A$ Jóia de África, que estreia em 2002, tornando-se a telenovela mais vista do canal privado TVI, cujo argumento, escrito por Manuel Arouca, torna-se a seguir um livro com o mesmo título. Um caso a parte é o programa de Joaquim Furtado, A Guerra, hoje existente também em DVD que pela primeira vez utiliza sistematicamente materiais de arquivo e entrevistas de ambas as partes num programa de grande divulgação televisiva.

É evidente que todos esses materiais acabam por, cada um à sua maneira, criar um repertório de imagens (tal como de narrativas feitas de palavras) que tentam responder aos muitos anos de recalcamento acerca dos últimos anos da presença portuguesa. O que nos interessa, perpassando uma demasiado fácil leitura e avaliação da qualidade deste tipo de materiais, é notar que tudo isto responde a uma crescente necessidade de criar um espaço de imagens da memória a partir do qual estamos prontos a lidar com realidades muitas vezes traumáticas do nosso passado colectivo.

\section{2.}

Se é verdade que a neutralidade de Portugal durante o segundo conflito mundial impediu ao País de medir militarmente forças com os exércitos de outros países, é verdade também que o surto das primeiras revoltas no Ultramar obrigou desde logo as Forças Armadas Portuguesas a uma confrontação militar muito dura. A integração de Portugal na NATO tinha vindo a formar uma elite militar que, como é noto, acabará por se contrapor politicamente ao regime. O regime de Salazar desde logo limitase a classificar as insurreições armadas no Ultramar como actos de terrorismo, mas também, para continuar a aguentar-se ao poder, silenciou durante muito tempo a real entidade do conflito. Dizer a guerra queria dizer admitir a existência de uma oposição organizada e como consequência admitir falhas no suposto unânime consenso ao regime salazarista. Toda a campanha do Estado Novo em relação à guerra apelavase assim a um choque frontal entre duas facções, um choque que não 
era capaz de deixar nenhum espaço àquela porosidade, que mesmo assim se estava a criar no dia a dia dos territórios ultramarinos.

As duas faces da guerra, documentário da jornalista portuguesa Diana Andringa e do realizador guineense Flora Gomes, tem como objectivo indagar exactamente este espaço comum, esta terceira margem que ao longo do conflito se foi criando na Guiné Bissau (se calhar a frente mais difícil para as Forças Armadas Portuguesas), teatro da acção de duas figuras muito carismáticas, a do português António Spínola e a de Amílcar Cabral que, em 1956, tinha fundado o PAIGCV, capaz de levar em poucos anos a questão colonial do Império português à atenção da comunidade internacional. Vale a pena lembrar que a Guiné Bissau é também, e não por acaso, a frente militar onde nasce o movimento dos Capitães de Abril. As duas faces da guerra explora exactamente a porosidade, o contacto, preferindo voltar a percorrer não as fracturas, as contraposições do conflito mas, por contra, aquele espaço intermédio que foi capaz de tornar possível a mudança e de certa forma a revolução por ambos as partes. Tenta ultrapassar a dimensão da guerra de memórias visando um possível espaço comum de recordo. A ideia nasce em 1995, quando Diana Andringa vai a Gheba. Decide assim fazer um filme a duas vozes, e propõe o seu projecto ao realizador guineense Flora Gomes. Aparentemente cada um conta a sua história, a sua parcela de história, de acordo com a sua naturalidade, mas ao longo do documentário os pontos de vista acabam por se matizar e confundir um dentro do outro. As primeiras imagens do filme mostram uma pedra encontrada em Gheba, na qual estão gravadas as datas de óbito de alguns soldados portugueses. Aquilo que é suposto ser um registo meramente documental abre-se logo para uma dimensão narrativa: para ler os nomes dos que caíram em combate, é preciso limpar, simbolicamente quase como quem volta a percorrer as camadas da sua própria memória, o pó e a terra que tornam impossível a leitura. Um dos militares tinha sido morto no dia em que Diana Andringa, a narradora da "parte portuguesa" fazia vinte anos. Ela não se vê, mas se ouve a sua voz e entendemos logo que estamos perante a tentativa de desvendar e recompor ao mesmo tempo as razões da história de uma inteira geração, onde o individual e o colectivo acabam por confundir-se, de uma geração em que, mesmo quem não participou directamente na epigonal gesta ultramarina ficou por ela atravessada, malgré tout. Durante seis semanas Diana Andringa e Flora Gomes viajam pelas regiões guineenses de Mansoa, Gheba e Guilegar e por Cabo Verde e Portugal, à procura das falas de quem viveu em primeira pessoa a experiência da guerra. $O$ lema mais ou menos explícito que acompanha a sequência das imagens é a celebre frase de Cabral na qual ele afirma que a guerra de libertação é travada contra o colonialismo e não contra o povo português. De facto, o que fica explicito no filme é que a guerra se conclui com duas vitórias, por ambas as partes, como se a partir de um certo momento os dois povos em guerra tivessem começado uma aventura a dois que levaria ambos para um futuro finalmente mais democrático.

E é este o elemento que considero fulcral do documentário: o revelar que é importante fazer emergir a fala do "inimigo" e que apenas através daquela fala - tal como demonstraram boa parte das tentativas operadas pelas muitas comissões de reconciliação nacional instituídas em países que passaram por dramáticas crises internas, quando não guerras 
fratricidas - que se vai conseguir reconstruir um chão comum.

Não cabe aqui entrar na definição das diferenças entre filme e cinema documentário (diferenças, porém, em boa parte ligadas a critérios estéticos que ainda se movem no horizonte de uma visão que se apega a uma certa ideia de representação do real como dimensão objectiva do próprio acto de narrar), mas o que é evidente é a intenção narrativa de propor uma outra narrativa possível, resultante exactamente das falas, da fragmentação necessária da memória interna de cada uma das partes do conflito. Como a própria voz narradora do filme diz no início de $A s$ Duas Faces da Guerra, a coisa mais surpreendente, uma vez chegados no terreno, foi registar a ausência de ódio. E esta sensação permanece ao longo das falas de entrevistados muito diferentes entre eles, que, depois do relato da primeira revolta do porto de Pidjiguiti, contam as suas historias: Amílcar Domingues é um português que aceita falar da guerra na rádio quebrando o silêncio imposto pelo regime, Vasco Lourenço, um dos capitães de Abril, afirma sem hesitação possível que depois de estar algum tempo na frente de combate da Guiné sentiu com força que "estava a mais naquele que não era o seu pais", outros militares declaram que a sua formação política começou exactamente na guerra. Ao lado destas estórias se juntam as de médicos portugueses que tinham desertado em Angola e que trabalhavam clandestinamente em hospitais de apoio ao PAIGCV, ou de médicos que, como Manuel Boal, mesmo estudando para a sua especialidade em Dakar prestava serviço aos feridos nas zonas de fronteira ou levava os doentes mais graves para o Senegal. Ou ainda o caso da sua mulher Lylica, que trabalhou incansavelmente nas campanhas de alfabetização da população das zonas libertadas, com o auxílio de um português exilado na Suécia para fugir à tropa, Fernando Baguinha, que elabora manuais escolares mais adequados à realidade guineense e aos ideais revolucionários do PAIGCV. Às imagens onde são contadas estes primeiros passos da nascente Nação guineense, atravessadas como elas são pela incansável acção dos militantes antifascistas e anticolonialistas, se contrapõem com força os recordos como que parados no tempo de dois antigos soldados portugueses, Leonel Martins e Pedro Gomes, que num café da província voltam a ver, como se ainda fosse a primeira vez, as imagens de um ataque durante o qual é morto um amigo. Trata-se de imagens extremamente cruas, em que um grupo de militares muito novos, tenta prestar socorro a um grupo de soldados gravemente feridos numa acção de combate. Este grupo de jovens evidentemente desamparados, que assistem à morte em directo, dia após dia, também do próprio sonho imperial, revela com força a real dimensão do conflito gerido no seu quotidiano por tropas formadas por homens na verdade pouco mais que adolescentes, lançados no mato a combater em uma guerra anacrónica cuja dimensão real foi escondida até ao fim. Imagens que pouco condizem com as que vinham mostradas na Metrópole nas quais, por exemplo, para frisar a natural vocação multirracial do império português, se filmavam, ainda nos primeiros anos 70, cenas do recrutamento (mais ou menos forçado) da população local, o qual tinha como finalidade antes de tudo criar fracturas dentro das comunidades locais levando, por outro lado, à hipérbole o discurso imperial de um Ultramar onde gcabiam $h$ todas as raças.

"Há que se falar", diz um dos mais velhos entrevistados no documentário e acrescenta: "Os tugas tinham força mas não tinham 
razão". Percorrer a sua história pode unir um povo, como nos demonstra um dos guerrilheiros entrevistados, no momento do reencontro com militares, eles também guineenses, mas que combateram ao lado dos portugueses, ao afirmar que "Guerra é guerra, agora viramos família outra vez". Mas como nos lembra a escritora nigeriana Chiamamanda Ngozi Adiche, para cancelar a história de um povo chega que outra pessoa decida contar, no seu lugar, a sua história. A história única, que não consegue acolher as diferentes falas de que se compõe, dificilmente pode ser servir de espelho comum de um povo à procura de uma identidade comum. $\mathrm{E}$ se calhar é também por isso que no documentário à primeira imagem da pedra de Gheba, onde se encontram gravados os nomes de militares caídos em combate, se contrapõe, quase naturalmente, a imagem do "Caminho do povo", isto é, do caminho onde, por baixo de árvores, se encontram sepultados na Guiné, anónimos mortos em combate. Mas que, um após o outro, passo depois passo, construíram o caminho da Nação libertada.

\section{3.}

Perante a "saturação do espectador", como dizia Edward Said, isto é, perante o horror e a vergonha dos epígonos da gesta imperial, durante muitos anos gerou-se, como já disse, em Portugal uma aparente indiferença em relação à questão. Um recalcamento, uma verdadeira operação de Verdrängung para utilizar um termo freudiano, tragicamente parecido com o silêncio do regime. As imagens, como nos lembra o realizador mauritano Abderaman Sissako não tem nacionalidades, mas podem "significar" politicamente, prescindindo mais facilmente daquela construção sintáctica imposta pela escrita. Impõe-se obviamente um igual problema de linguagem, de comonarrar uma história, mas, tal como no acto tradutivo, as imagens nos remetem de maneira mais imediata e quase instintiva, para partes, muitas vezes vestígios, dos nossos arquivos de memória, fragmentados mas capazes de evocar, e com muita força, totalidades. Como no projecto "Necessita dei volti", é muitas vezes a prova da existência do inimigo que manifesta e revela as raízes do conflito.

E o recalcamento não é apenas de Portugal, mas, salvo algumas excepções, parece ter sido "exportado" ao antigo espaço colonial, considerada a ainda escassa produção de uma literatura sobre a guerra e, de igual maneira, de uma cinematografia - excepção feita pelo filme de Zezé Gamboa O Herói (2004) e de Terra Sonâmbula(2007) de Teresa Prata, capaz de narrar as guerra civis que atravessaram tais países durante muitos e muitos anos. É curioso que um escritor como Luandino Vieira, no seu regresso à escrita, tenha vindo a escrever sobre a guerra em $O$ livro dos rios (2006), como em O livro dos guerrilheiros (2009). E tenha prestado muita atenção ele também à questão do inimigo, se calhar para compreender a própria génese da Nação independente.

No fundo é apenas o inimigo quem, qual espelho mágico, nos enuncia o que realmente somos, e contra que estamos realmente a lutar. 


\section{REFERÊNCIAS BIBLIOGRÁFICAS}

ADICHE, Chiamamanda Ngozi. "O perigo da história única". Disponível em: www.ted.com/talks/lang/por_pt/himamanda_adichie_the_danger _of_a_single_story.html .

ANDRINGA, Diana; GOMES, Flora. As Duas Faces da Guerra, 2007.

BOTELHO, João. Um Adeus Português, 1986

CARDOSO, Margarida. A costa dos murmúrios, 2004.

CARDOSO, Margarida. Natal 71, Midas Filmes, 2000.

GAMBOA, Zezé. O Herói, 2004

PRATA, Teresa. Terra Sonâmbula, 2007.

RTP- Televisão portuguesa. "A Guerra", DVD, organizado por Joaquim Furtado, 2009.

VASCONCELOS, António Pedro. Os Imortais, 2000. 